\title{
Utilization of Plastics Waste Oil as Partial Substitute for Kerosene in Pressurized Cookstoves
}

\author{
Harwin Saptoadi and Nosal N. Pratama
}

\begin{abstract}
The aims of the research are to recycle plastic wastes into combustible oil and utilize it in cookstoves. One of simple recycling methods is pyrolysis. Substantial volume of pyrolytic oil can be obtained along with ignitable gas and residual char. The composition and quality of these three products can be improved with an additional catalytic reforming process. Specifically, this research utilizes indigenous natural zeolite as catalyst, while the primary raw material is Polyethylene. Variations in the raw materials are conducted by adding smaller quantity of other plastic materials. The maximum temperature in the fixed bed pyrolyzer and the reformer are $5_{00}^{\circ} \mathrm{C}$ and $450^{\circ} \mathrm{C}$, respectively. Nitrogen with 0.8 $1 / \mathrm{min}$ flow rate is applied as the carrying medium. The results show that pyrolytic oil obtained from Polyethylene has good calorific values but unfortunately low yield, thus its recovered energy is modest. Unintended mixing with other kinds of plastics will coincidentally help improving the attained thermal energy. Mass conversion rate of plastics-to-oil varies between $41 \%$ and $45 \%$. The oil is then exploited as partial substitute for kerosene used in cooking stoves. The experiments are carried out by blending 25 vol- $\%$ of pyrolytic oil with 75 vol- $\%$ of kerosene. The results show that firepower varies between 1,609 $\mathrm{W}$ and $1,651 \mathrm{~W}$, while the boiling time is almost constant at 23 min. The thermal efficiency fluctuates, corresponding to the heat, from $47.5 \%$ to $51.1 \%$, which do not differ significantly from $53.08 \%$ when $100 \%$ kerosene is used. It is expected that consumption of kerosene can be considerably reduced by partial substitution.
\end{abstract}

Index Terms - Cookstove, fuel substitution, kerosene, plastics waste, pyrolytic oil.

\section{INTRODUCTION}

There is a dilemma regarding plastics utilization. Actually, plastics are very useful and possess superior characteristics as materials, such as durability, light weight, corrosion resistant, low cost, processability, etc. Therefore, it is fully understood if they are exploited massively for almost all purposes in human daily activities. Unfortunately, after their satisfying usage they become highly problematical wastes due to their awfully poor ability to degrade. Plastics made from polyethylene (including HDPE and LDPE) are mostly found and thus represent the largest constituent of wastes, followed by polypropylene (PP), polystyrene (PS), polyethylene terephthalate (PET) and Others (symbol number 7). In order

Manuscript received May 10, 2014; revised August 11, 2014. This work was supported in part by the JICA (Japan International Cooperation Agency), under CRI program of AUN/SEED-Net, during October 2011 March 2013. Another supporting institution is Dompet Dhuafa.

Harwin Saptoadi is with the Department of Mechanical and Industrial Engineering, Gadjah Mada University, Yogyakarta, Indonesia (e-mail: harwins@ugm.ac.id).

Nosal N. Pratama was with the Department of Mechanical and Industrial Engineering, Gadjah Mada University, Yogyakarta, Indonesia (e-mail: nosalpratama@yahoo.com). to reduce plastics demand and production, immense campaigns are carried out worldwide to switch from plastics to more environmental friendly materials. Furthermore, considering its utmost durability, plastics must be reused many times prior to recycling. Those which cannot be recycled go to final disposal sites. These disposal areas would be fully occupied by plastic wastes in only a few years, unless successful methods to recycle them are found out and implemented immensely. Efforts are carried out to solve the problems, especially regarding the recyclable plastics. One of them is pyrolysis method, which becomes more popular due to its simplicity, since it does not require previous expensive treatments (such as cutting, shredding, grinding, drying, etc.), cleaning up and segregation. However, a considerable amount of heat is needed for thermal decomposition of plastics into shorter chain structures. Commercially operated plastics pyrolysis plants are successful to keep the required thermal energy low and less than the energy contained in their products. One of examples is a plant which started its operation in 2000 and capable of producing light, medium and heavy oils, along with by-products such as Hydrogen Chloride, pellets and flammable gas [1]. Substantial volume of combustible hydrocarbon oil will be obtained and ready for another purpose as simple fuels. In addition, light hydrocarbon fractions will yield as useful flammable gas and small amount of residual solid char will remain in the bottom of pyrolysis reactor. Efforts are always done to improve the composition and quality of these three products. Generally, more oil and fewer gas yield is expected. Besides, the oil characteristics should resemble those of conventional liquid fuels. In this case, additional catalytic reforming process is applied. The presence of catalysts can help reducing the degradation temperatures, lowering the activation energy (hence increasing cracking rate and shortening residence time), improving the quality of yields, etc. [2]. Various available catalysts can be selected appropriate to the desired product quality. There are natural and synthetic catalysts, where the former is obviously cheaper than the latter. A research using $\mathrm{PE}$ and $\mathrm{PS}$ proved that if the optimum temperature for thermal cracking was $410^{\circ} \mathrm{C}-430^{\circ} \mathrm{C}$, lower temperature, around $390^{\circ} \mathrm{C}$, could be used for catalytic cracking [3]. Lee conducted investigation without and with catalyst, called FCC (fluid catalytic cracking) catalyst. Improvement of liquid and gas yield was observed. Even spent FCC catalyst could still contribute to a relatively good effect [4].

Previous researches have been carried out to convert plastic wastes into oil by means of pyrolysis process. These investigations unveil several interesting phenomena and parameters which greatly influence the oil yield. The most affecting variables are pyrolysis temperature and time. 
Temperature has a strong effect on the characteristics of pyrolysis liquid, such as viscosity and hydrocarbon chain. An experiment with municipal mixed plastic wastes showed that the best combination of temperature and residence time was $500^{\circ} \mathrm{C}$ and 15 - 30 minutes in order to achieve total conversion of plastics residue [5]. Another experiment with municipal plastic wastes also demonstrated the effects of temperature and time, however the maximum temperature applied in the research was $450^{\circ} \mathrm{C}$. The characteristics of collected pyrolytic liquid were comparable to those of commercial oil (gasoline, diesel and kerosene) [6]. Another researcher highlighted the influence of temperature and time as well after carrying out pyrolysis of LDPE, PS and their mixture. Temperature variations of between $300^{\circ} \mathrm{C}$ and $500^{\circ} \mathrm{C}$ were selected. LDPE was degraded to oil at $425^{\circ} \mathrm{C}$, however higher temperatures would lead to less liquid due to its conversion to char and gas. PS was degraded at around $350^{\circ} \mathrm{C}$, but under increasing temperatures and times the oil yield was preferentially converted to char. Reasonably, their mixtures would reduce the degradation temperature of LDPE and increase the liquid yield [7]. Previously, it was recognized as well that temperatures and time affected the yield and structure of the pyrolysis products, while the chemical structure of the wastes had a considerable effect on the properties of the products. Around 10\% - 25\% of liquid could be obtained, but an increase of $10 \%-15 \%$ could be expected by distillation [8].

Furthermore, it is well understood if end product yields and properties depend strongly on the plastic wastes composition, as shown in a research using PE, PS and PP. Both PS and PP increased the octane number of liquid product. Therefore, the desired end product could be acquired by appropriate blending in the pyrolysis reactor [9].

The obtained pyrolytic liquid can be utilized as fuels, although it is recommended to blend with commercial fuels prior to its usage. Numerous researches have been carried out to investigate its utilization in internal combustion engines, especially in diesel engines. The performance of blended fuel diesel engines gave quite good results [10]. In spite of this, many engine owners may be reluctant to make use of the blended fuel due to their concern with engine lifetime. An alternative is considered where the pyrolytic liquid is used as blended fuel for pressurized kerosene cookstoves. It is apparent that fuel specification is not as strict as that for automotive engines, because cooking stoves are very much cheaper. If $100 \%$ pyrolytic oils are not as excellent as kerosene, they can be blended with kerosene. In this way, kerosene consumption can be reduced substantially due to partial substitution.

A research has been done by Visser to determine firepower and efficiency of various cookstoves with the help of simple WBT (water boiling test). There were high and low power regimes, which occurred before and during boiling process. The results could be used to calculate fuel consumption with good accuracy, as shown by measurements in Senegal and Mauritania [11]. Efforts to fully replace kerosene with Fatty Acid Methyl Esters from oil plants, e.g. soyabeans, sunflower, coconut, physic nut, etc., have been conducted in another research by Wagutu et al. on domestic cooking wick stoves. The WBT was applied as well to compare the stove performances with that using kerosene. It was disclosed that an average firepower of $1095 \mathrm{~W}$ was around $20 \%$ lower than that of kerosene, whereas the average specific fuel consumption was 55\% higher [12]. Another researcher tried to compare ethanol with kerosene as cookstove fuels. Kerosene generated more heat than ethanol and therefore took shorter time to boil the same quantity of water. It could be caused by the presence of water vapour in the combustion zone as a result of ethanol-water mixture which reduces the maximum heat attained by the burner. It could also be resulted from fewer number of carbon atoms in the molecules of ethanol. It was concluded that kerosene stoves demonstrated higher efficiency, lower start up cost and higher fuel economy [13]. Performances of fifty cooking stoves have been measured using the WBT method. However they were almost exclusively fired with solid fuels, whereas only one was a non-pressurized kerosene wick stove. No measurement was done on pressurized one. Kerosene wick stove exhibited less energy consumption and emissions, e.g. $\mathrm{CO}$ and Particulate Matter, which were apparently lower than the benchmarks. In order to complete WBT, the required energy was $9.7 \mathrm{MJ}$, the $\mathrm{CO}$ emission was around $8 \mathrm{~g}$ and the PM was $10 \mathrm{mg}$. The benchmarks for these were $15 \mathrm{MJ}, 20 \mathrm{~g}$ and $1500 \mathrm{mg}$, respectively [14].

A pilot program, called Indonesian Clean Stove Initiative (ICSI), has been launched recently. Although it is intended mostly for biomass fuel, but it applies for kerosene fuel as well, especially in some key performance metrics, such as thermal efficiency, CO and PM emissions, and safety. Based on the standardized test, cookstoves can be classified into one star, two star or three star ratings. ICSI clearly makes a distinction between Cooking Stove and Water Boiler, which really perform differently [15].

Kerosene is one of excellent fuels for cooking stoves, particularly due to its superior thermal performance compared to biomass fuels [12]-[14]. Furthermore, widespread use of kerosene can significantly reduce the deforestation rate in third world countries, which still depend heavily on firewood and biomass for fuels. However, kerosene belongs to fossil fuel which is alarmingly depleted and carbon-emitting. It becomes less popular, especially when its price increases due to government's non-subvention policy. Less consumption of kerosene should be the wish of every cookstove user.

The paper describes the results of three experiments, i.e. pyrolysis of plastics residue to yield oil (chapter II), utilization of the oil as alternative fuel in pressurized cookstoves according to WBT (chapter III), and practical cooking for obtaining hot water (chapter IV). However, the pyrolytic liquid is not solely used as fuel, but mixed with kerosene with a volumetric ratio of $25 \%: 75 \%$. It is expected that problems concerning huge amount of plastic residues and depletion of fossil fuels for cooking can be solved at the same moment by such a partial substitution.

\section{Research ON Plastics-TO-OIL}

\section{A. Materials and Equipment}

The raw materials (feedstocks) are plastic wastes made from PE (polyethylene), PP (polyprophylene), PS (polystyrene), PET (polyethylene terephthalate), and Others (symbol number 7), which are collected from several places 
around Yogyakarta city. They are real wastes, but previously have been sufficiently cleaned by waste scavengers. Those raw materials are varied in their compositions as shown in Table I.

TABLE I: VARIATIONS OF RAW MATERIALS FOR PYROLYSIS

\begin{tabular}{|c|c|c|c|c|c|}
\hline \multirow{2}{*}{ Samples } & \multicolumn{5}{|c|}{ Mass Fractions (\%) } \\
\cline { 2 - 6 } & PE & PP & PS & PET & Others \\
\hline A & 100 & 0 & 0 & 0 & 0 \\
\hline B & 60 & 40 & 0 & 0 & 0 \\
\hline C & 50 & 40 & 10 & 0 & 0 \\
\hline D & 50 & 30 & 5 & 10 & 5 \\
\hline
\end{tabular}

The initial total mass of sample A is $2 \mathrm{~kg}$, whereas other samples are $1.5 \mathrm{~kg}$. The reason is the higher density of PE, so that heavier material can be contained in the same reactor volume. Accordingly, the catalyst for sample A weighs $400 \mathrm{~g}$ and for others $300 \mathrm{~g}$, because the Plastic/Catalyst mass ratio is kept constant at 5. It is apparent that PE is the primary material in the research, as observed commonly in the reality. The sample D should resemble typical mixed wastes in real disposal sites.

The catalyst used in the research is natural zeolite obtained from the nearby Klaten regency and activated prior to its usage by calcinations in order to remove moisture and increase its surface area [10]-[16]. The experimental set up is schematically shown in Fig. 1.

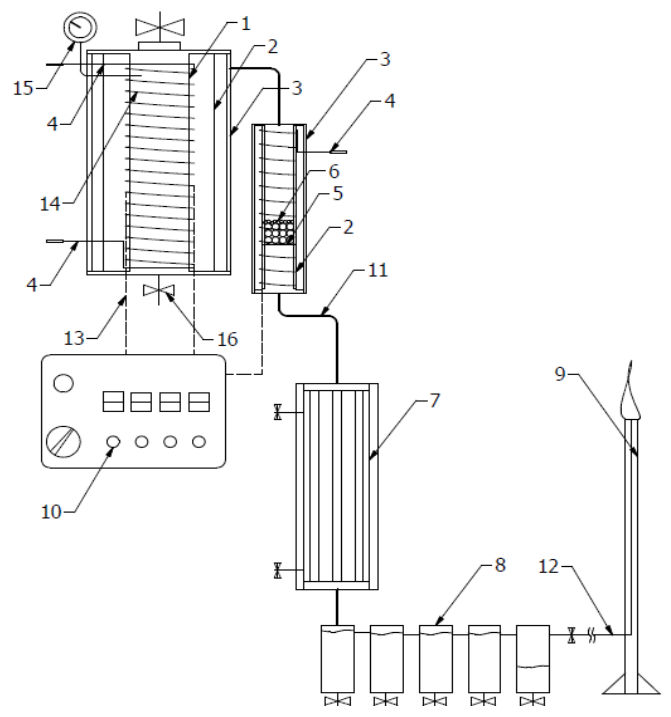

Remarks:

1. Batch Reactor

2. Castable Isolator

9. Flare

3. Aluminum Foil isolator

4. White Glasswool isolator

10. Temperature control

11. Stainless pipe

12. Plastic pipe

13. Electrical wire

14. Nikelin coil

6. NZ catalys

7. Condenser

8. Oil tank

15. Pressure gage

16. Nitrogen Valve

Fig. 1. Experimental set up for plastic pyrolysis [10]-[16].

\section{B. Research Procedures}

The first experiments are carried out in two sequences, i.e. thermal degradation (in the batch reactor with a maximum temperature of $500^{\circ} \mathrm{C}$ ) and catalytic reforming with a highest temperature of $450^{\circ} \mathrm{C}$. These high temperatures are kept constant and achieved by electric resistance heaters coiled around the reactors. These heaters consist of $2 \times 1000 \mathrm{~W}$ for thermal and $2000 \mathrm{~W}$ for catalytic crackings. Nitrogen is used as carrier gas with a constant flow rate of $0.8 \mathrm{l} / \mathrm{min}$. The yield gas is then condensed partially and collected in oil tanks. The non-condensable gas is finally flared.The pyrolysis process is terminated if there is no condensing oil anymore. The solid residue and liquid oil are weighed, whereas the mass of flared gas is estimated by taking the total initial mass of plastic wastes into account.

\section{Results and Discussions}

Compositions of the pyrolysis products are displayed in Table II. The measured heating values of the oils are also shown in Table II.

TABLE II: COMPOSITIONS OF YIELDS AND OIL'S HV

\begin{tabular}{|c|c|c|c|c|}
\hline Samples & $\begin{array}{c}\text { Pyrolytic } \\
\text { Oil } \\
(\%)\end{array}$ & $\begin{array}{c}\text { Flared Gas } \\
(\%)\end{array}$ & $\begin{array}{c}\text { Residual } \\
\text { Char } \\
(\%)\end{array}$ & $\begin{array}{c}\text { Heating } \\
\text { Value } \\
(\mathrm{MJ} / \mathrm{kg})\end{array}$ \\
\hline $\mathrm{A}$ & 41.15 & 51.95 & 6.90 & 45.45 \\
\hline $\mathrm{B}$ & 42.40 & 53.93 & 3.67 & 44.53 \\
\hline $\mathrm{C}$ & 45.13 & 51.40 & 3.47 & 42.57 \\
\hline $\mathrm{D}$ & 43.40 & 50.67 & 5.93 & 44.26 \\
\hline
\end{tabular}

The highest oil yield is achieved by the sample $\mathrm{C}$, then followed by the sample D. The reason could be higher PS content, where the sample C contains $10 \%$, the sample D amounts to $5 \%$ and the rests no PS at all [7]. It happens probably due to intermediate radicals generated during the reaction which have higher molecular weights, corresponding to aromatic structure [9].

Considering the main goal of the research, i.e. conversion of plastics to oil, the results are not fully satisfying because the gas yield is still more than the oil. If cooling water temperature entering the condenser could be made lower, definitely more liquid would be collected in the oil tanks. Fortunately, the gas is combustible as well since it contains hydrocarbon. It seems that pure PE will produce least oil, but fortunately highest calorific value. Another source mentions that oils derived from pyrolysis of $100 \% \mathrm{PE}$ and pure PS have heating values of 52.3 and $50.4 \mathrm{MJ} / \mathrm{kg}$, respectively [17]. Therefore, addition of other plastic materials to PE wastes can increase the oil yield but decrease the heating value. Unintended mixing of PE with other kinds of plastics will coincidentally help improving the attained thermal energy per mass unit of raw material, as shown in Table III.

TABLE III: ENERGY CONTENT PER MASS UNIT OF RAW MATERIAL

\begin{tabular}{|c|c|c|c|c|}
\hline Samples & $\begin{array}{c}\text { Initial } \\
\text { mass of } \\
\text { feedstock } \\
(\mathrm{kg})\end{array}$ & $\begin{array}{c}\text { Obtained } \\
\text { oil } \\
(\mathrm{kg})\end{array}$ & $\begin{array}{c}\text { Obtained oil } \\
\text { per feedstock } \\
(\mathrm{kg} / \mathrm{kg})\end{array}$ & $\begin{array}{c}\text { Energy } \\
\text { content per } \\
\text { feedstock } \\
(\mathrm{MJ} / \mathrm{kg})\end{array}$ \\
\hline $\mathrm{A}$ & 2.0 & 0.823 & 0.4115 & 18.702 \\
\hline $\mathrm{B}$ & 1.5 & 0.636 & 0.4240 & 18.880 \\
\hline $\mathrm{C}$ & 1.5 & 0.677 & 0.4513 & 19.211 \\
\hline $\mathrm{D}$ & 1.5 & 0.651 & 0.4340 & 19.208 \\
\hline
\end{tabular}

Oil samples C and D are obviously better than others. It confirms that expensive waste segregation practices are unnecessary.

\section{OIL AS FUEL IN WATER BoILING TeST}

\section{A. Materials and Equipment}

The materials for the second experiments are oil samples A 
to $\mathrm{D}$ collected from the previous experiments. These oils are blended with kerosene with a volumetric ratio of 1: 3 prior to their application as cookstove fuel in the Water Boiling Tests. The fraction of pyrolytic oil in the fuel mixture must be low enough in order to avoid too much deviation in the fuel characteristics. Blended fuel, as much as $800 \mathrm{ml}$, is initially pressurized 3 bars in an oil tank. After completion of each test the fuel pressure goes down normally to 2.7 bars. Water volume at the beginning of each measurement amounts to about $2600 \mathrm{ml}$ [16]. The experimental set up is illustrated in Fig. 2.

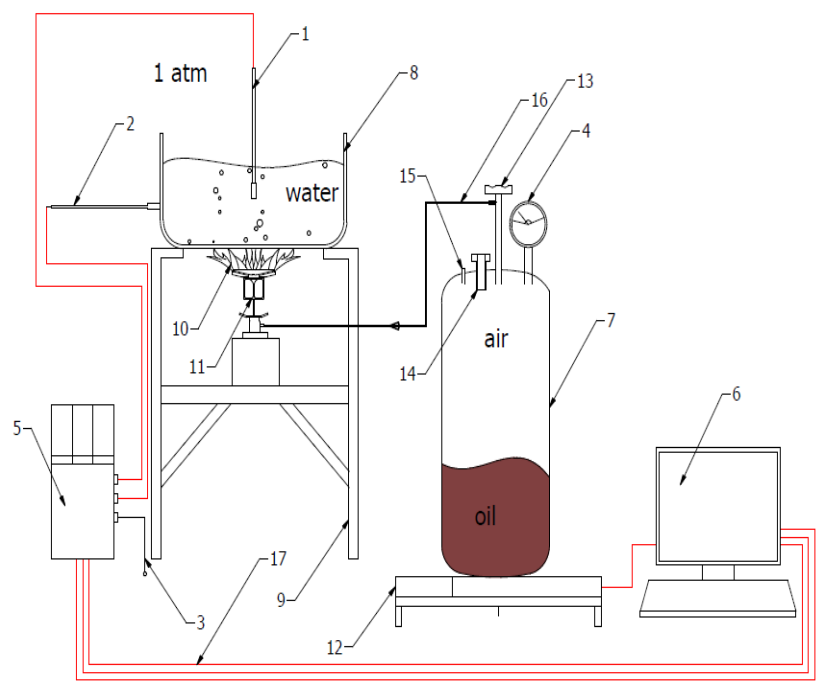

Remarks:

1. Thermocouple 1

10. Flame

2. Thermocouple 2

3. Thermocouple 3

4. Pressure gauge

5. Thermocontroller

11. Pressurized kerosene stove

12. Scale

13. Oil flow controller

6. Computer

7. Oil tank

14. Plug

15. Vent

16. Oil tube

8. Water pan

9. Stove frame

17. Electronic wires

Fig. 2. Experimental set up for WBT [16].

\section{B. Research Procedures}

At first, all fuels are analyzed to determine their physical properties, such as density and heating value. Water is heated from room temperature (assumed at $30^{\circ} \mathrm{C}$ ) until its boiling point with the help of blended fuel combustion heat. Then, let it simmer at approximately $98^{\circ} \mathrm{C}$ for 45 minutes. Water temperature changes and remaining oil mass are recorded every minute. Total fuel consumption and water evaporation for each case are observed for further analysis. Performance of pure kerosene is measured also to serve as a comparison. Afterward those data are calculated to find out fuel consumptions, energy release, fire power and efficiency.

\section{Results and Discussions}

The required time for boiling is about 23 minutes in all experiments. Therefore each test takes totally around 68 minutes. The measurement results are shown in the following Tables IV and V.

TABLE IV: FUEL CHARACTERISTICS AND ENERGY

\begin{tabular}{|c|c|c|c|c|}
\hline Samples & $\begin{array}{c}\text { Higher } \\
\text { Heating } \\
\text { Value } \\
(\mathrm{kJ} / \mathrm{kg})\end{array}$ & $\begin{array}{c}\text { Total fuel } \\
\text { consumed } \\
(\mathrm{kg})\end{array}$ & $\begin{array}{c}\text { Energy } \\
\text { released } \\
(\mathrm{kJ})\end{array}$ & $\begin{array}{c}\text { Fire Power } \\
(\mathrm{kW})\end{array}$ \\
\hline $\mathrm{A}+\mathrm{K}$ & $46,441.41$ & 0.1438 & $6,678.27$ & 1.6368 \\
\hline $\mathrm{B}+\mathrm{K}$ & $45,638.91$ & 0.1468 & $6,699.79$ & 1.6421 \\
\hline $\mathrm{C}+\mathrm{K}$ & $45,126.56$ & 0.1455 & $6,565.91$ & 1.6092 \\
\hline $\mathrm{D}+\mathrm{K}$ & $45,507.33$ & 0.1461 & $6,648.62$ & 1.6295 \\
\hline $\mathrm{K}$ & $46,894.17$ & 0.1437 & $6,738.69$ & 1.6516 \\
\hline
\end{tabular}

It is noteworthy that heating values of the pyrolytic oils are only slightly lower than that of kerosene. Therefore, blending pyrolytic oils with kerosene does not reduce the calorific values too much. Basically, fuels with better heating values are less consumed in order to perform the same task, except for the samples $\mathrm{B}+\mathrm{K}$ and $\mathrm{C}+\mathrm{K}$ which behave differently. The generated thermal energy is calculated by multiplying heating values with total fuel consumptions. Fire power is the average power output of the stove during WBT [12]. Firepowers calculated in the research are in good agreement with the results of others [12]. Higher values obtained in this research are caused by pressurized supply of fuel (which means more fuels) instead of natural capillary flow through wicks in conventional kerosene stoves [13].

TABLE V STOVE PERFORMANCES

\begin{tabular}{|c|c|c|c|c|}
\hline Samples & Initial Water mass $(\mathrm{g})$ & Evaporated Water $(\mathrm{g})$ & Energy for Boiling (kJ) & Efficiency (\%) \\
\hline $\mathrm{A}+\mathrm{K}$ & $2,621.40$ & $1,181.30$ & $3,415.45$ & $51.14 \%$ \\
\hline $\mathrm{B}+\mathrm{K}$ & $2,660.49$ & $1,158.49$ & $3,375.12$ & $50.37 \%$ \\
\hline $\mathrm{C}+\mathrm{K}$ & $2,633.00$ & $1,048.60$ & $3,119.20$ & $47.50 \%$ \\
\hline $\mathrm{D}+\mathrm{K}$ & $2,632.00$ & $1,120.00$ & $3,280.10$ & $49.33 \%$ \\
\hline $\mathrm{K}$ & $2,699.00$ & $1,243.00$ & $3,576.90$ & $53.08 \%$ \\
\hline
\end{tabular}

Normally, higher fire power will evaporate more water, but not including the sample $\mathrm{B}+\mathrm{K}$ which is unusual. The reason is probably the higher initial mass of water compared to the sample $A+K$, which makes more energy is used to raise its temperature and less for evaporation. Energy is absorbed and used by the water firstly to increase its temperature, from ambient up to saturated temperatures, and secondly to change its phase. The specific heat of water is $4.2 \mathrm{~kJ} / \mathrm{kg}^{\circ} \mathrm{C}$ and its latent heat is $2257.5 \mathrm{~kJ} / \mathrm{kg}$. Energy for heating up the metallic water pot is considered small and thus neglected. Efficiency is the ratio of useful, absorbed energy by water to released energy from fuel combustion, which shows how good the stove is to transfer heat from fire to water. The stove using
$100 \%$ kerosene performs the best among others, whereas that using $\mathrm{C}+\mathrm{K}$ shows the least success. It is not surprising because the stove is specially designed for pure kerosene, not for blended fuels. Highest efficiency for kerosene stove can be achieved possibly due to highest flame temperature which leads to better convection and radiation heat transfers to water in the pan. Efficiencies measured in the research are in good agreement with the results of others [11], [12]. Higher efficiencies achieved in this research are caused by pressurized supply of fuel instead of natural capillary flow through wicks in conventional kerosene stoves.

In contrast to the result of the first experiment (chapter II), the samples $\mathrm{C}+\mathrm{K}$ and $\mathrm{D}+\mathrm{K}$ are not preferred from the WBT 
point of view.

\section{PRACTICAL COOKING FOR Hot WATER}

In the reality, especially in Indonesian households, most people heat up water until it boils, then immediately put the fire off, and finally use the hot water for drinking or other purposes. Simple stoves function only as a water boiler [15] and therefore are not equipped with any switch to adjust their firepowers. High temperature is expected to deactivate microorganisms which naturally exist in raw water. In such case WBT is not suitable for calculating the stove performance. The simmering period of 45 minutes is practically not required and therefore only an energy wastage. It only makes less water available at the end, because more has been vaporized uselessly. The required fuel in this research is correspondingly only $33.82 \%$ of the complete WBT. Specific fuel consumption is here preferred to represent the stove performance. It shows the amount of fuel required to produce an output unit, i.e. $1 \mathrm{~kg}$ of boiled water [12]. Fig. 3 shows equipment arrangement for the simple cooking process. Components appeared in the Fig. 3, such as pressurized cookstove, water pan, stove frame, oil tube and thermocouples are exactly the same as those already shown schematically in Fig. 2. The calculation results are displayed in the following Table VI.

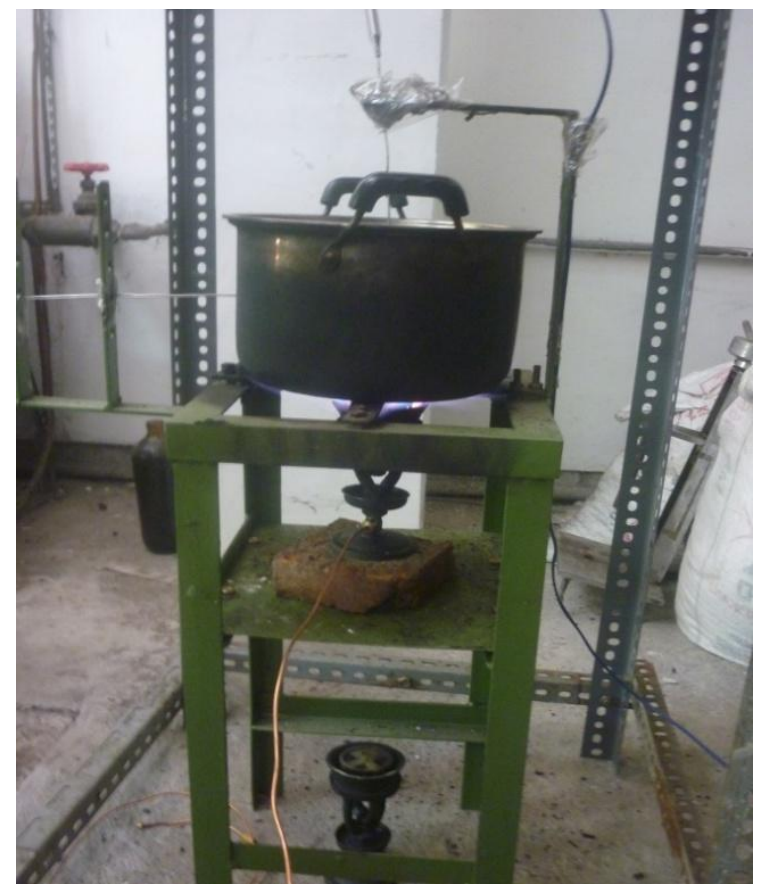

Fig. 3. Cookstove to boil water.

TABLE VI: SPECIFIC FUEL CONSUMPTION

\begin{tabular}{|c|c|c|c|}
\hline Samples & $\begin{array}{c}\text { Available Hot } \\
\text { Water } \\
(\mathrm{g})\end{array}$ & $\begin{array}{c}\text { Fuel for } \\
\text { Boiling } \\
(\mathrm{g})\end{array}$ & $\begin{array}{c}\text { Specific fuel } \\
\text { consumption } \\
(\mathrm{g} / \mathrm{g})\end{array}$ \\
\hline $\mathrm{A}+\mathrm{K}$ & $1,440.1$ & 48.638 & 0.0337 \\
\hline $\mathrm{B}+\mathrm{K}$ & $1,502.0$ & 49.653 & 0.0330 \\
\hline $\mathrm{C}+\mathrm{K}$ & $1,584.4$ & 49.213 & 0.0310 \\
\hline $\mathrm{D}+\mathrm{K}$ & $1,512.0$ & 49.416 & 0.0326 \\
\hline $\mathrm{K}$ & $1,456.0$ & 48.604 & 0.0333 \\
\hline
\end{tabular}

It is obvious that the samples $\mathrm{C}+\mathrm{K}$ and $\mathrm{D}+\mathrm{K}$ show better performance than others, even if compared to pure kerosene. Partial substitution of kerosene is going to be highly advantageous, both environmentally and economically. As discussed in the first experiment (chapter II), samples C and D prove again their superiorities as fuel.

\section{FUTURE WORKS}

Despite of those promising results, many research works must be carried out in the future for significant improvement. Efforts to increase oil quantity and quality are essential in order to make it economically feasible. Appropriate blend of various plastic feed stocks must be determined in order to obtain oils which closely resemble conventional fossil fuels, such as gasoline, diesel oil, fuel oil and kerosene, in terms of their physical and thermal characteristics, e.g. specific gravities, kinematic viscosities, pour point, flash point, cloud point, heating values, etc. If blended fuel is not necessary anymore, because waste plastic pyrolysis oil performs exactly as pure kerosene, then full replacement of kerosene can be realized. The next dream would be utilization of waste plastic oils as partial substitute for gasoline and diesel fuels.

Another concern is energy balance of the process. Researches must be continuously done to reduce the required thermal energy for pyrolysis. In order to achieve the dream, pyrolysis process is expected to occur as swift as possible, whereas the temperature should be as low as possible. The produced hydrocarbon gas can be used to supply partially the required energy. The main energy source should not be expensive electricity but cheap fuels, e.g. charcoal and biomass wastes [18].

\section{CONCLUSIONS}

Huge amount of plastic wastes must be trimmed down. Pyrolysis is one among several promising recycling methods. Pyrolysis of waste plastics made from PE can produce good fuel oils. Unintended mixing with other kinds of plastics, especially PS, can coincidentally yield even better fuel. Higher PS content can help improving the oil quality. Therefore, costly waste segregation prior to pyrolysis is not required. The heating values of these oils are only slightly lower than kerosene. For that reason, these pyrolytic oils can be blended with kerosene in a volumetric ratio of $1: 3$, and used as fuel for cookstoves. Unfortunately, the standard Water Boiling Test does not demonstrate satisfying results for oils from PS-containing wastes. The reason is that WBT procedure includes 45 minute simmering course, which is not required in real daily cooking activities in most countries. Considering that most cookstoves are operated merely as water boiler, another simple experiment is carried out. Again, oils derived from PS-containing wastes prove their superiorities. This research can convince cookstove users that partial substitution of kerosene with plastics oil is advantageous and also practicable to save fossil fuels, environment and money. Despite of the promising results, many research works must be carried out in the future for significant improvement and full substitution of kerosene.

\section{ACKNOWLEDGMENT}

The authors would like to gratefully thank Prof. Kunio Yoshikawa from the Tokyo Institute of Technology, Japan, 
for his continuous support and supervision of the research. Prof. Wega Trisunaryanti from Gadjah Mada University and Prof. Zainal Alimuddin from Universiti Sains Malaysia have contributed greatly to the research as well. Furthermore, Harwin Saptoadi thanks his master students, particularly Mochamad Syamsiro, for their excellent supports as research assistants.

\section{REFERENCES}

[1] M. Fukushima, M. Shioya, K. Wakai, and H. Ibe, "Toward maximizing the recycling rate in a Sapporo waste plastics liquefaction plant," Journal of Material Cycles Waste Management, vol. 11, pp. 11-18, 2009.

[2] J. Aguado and D. Serrano, Feedstock Recycling of Plastic Wastes, Royal Society of Chemistry, Clean Technology Monographs, ch. 5, pp. 129-130, 1999.

[3] J. Walendziewski and M. Steininger, "Thermal and catalytic conversion of waste polyolefins," Catalysis Today, vol. 65, pp. 323-330, 2001

[4] K. H. Lee, "Thermal and catalytic degradation of pyrolytic oil from pyrolysis of municipal plastic wastes," Journal of Analytical and Applied Pyrolysis, vol. 85, pp. 372-379, 2009.

[5] A. Lopez, I. de Marco, B. M. Caballero, M. F. Laresgoiti, and A. Adrados, "Influence of time and temperature on pyrolysis of plastic wastes in a semi-batch reactor," Chemical Engineering Journal, vol. 173 , pp. 62-71, 2011

[6] K. H. Lee, "Thermal degradation of heavy pyrolytic oil in a batch and continuous reaction system," Journal of Analytical and Applied Pyrolysis, vol. 86, pp. 348-353, 2009.

[7] J. A. Onwudili, N. Insura, and P. T. Williams, "Composition of products from the pyrolysis of polyethylene and polystyrene in a closed batch reactor: Effects of temperature and residence time," Journal of Analytical and Applied Pyrolysis, vol. 86, pp. 293-303, 2009.

[8] N. Miskolczi, L. Bartha, G. Deak, and B. Jover, "Thermal degradation of municipal plastic waste for production of fuel-like hydrocarbons," Polymer Degradation and Stability, vol. 86, pp. 357-366, 2004.

[9] F. Pinto, P. Costa, I. Gulyurtlu, and I. Cabrita, "Pyrolysis of plastic wastes. 1. Effect of plastic waste composition on product yield," Journal of Analytical and Applied Pyrolysis, vol. 51, pp. 39-55, 1999.

[10] N. N. Pratama and H. Saptoadi, "Characteristics of waste plastics pyrolytic oil and its applications as alternative fuel on four cylinder diesel engines," International Journal of Renewable Energy Development, vol. 3, no. 1, pp. 13-20, 2014.

[11] P. Visser, "The testing of cookstoves: Data of water-boiling tests as a basis to calculate fuel consumption," Energy for Sustainable Development, vol. IX, no. 1, pp. 16-24, 2005.

[12] A. W. Wagutu, T. F. N. Thoruwa, S. C. Chhabra, C. C. Lang'at-Thoruwa, and R. L. A. Mahunnah, "Performance of a domestic cooking wick stove using fatty acid methyl esthers from oil plants in Kenya," Biomass and Bioenergy, vol. 34, pp. 1250-1256, 2010.

[13] I. J. Dioha, C. H. Ikeme, N. Tijjani, and E. C. Dioha, "Comparative studies of ethanol and kerosene fuels and cookstoves performance," Journal of Natural Sciences Research, vol. 2, no. 6, pp. 34-38, 2012.
[14] N. MacCarty, D. Still, and D. Ogle, "Fuel use and emissions performance of 50 cooking stoves in the laboratory and related benchmarks of performance," Energy for Sustainable Development, vol. 14, pp. 161-171, 2010.

[15] ICSI (Indonesian Clean Stove Initiative) pilot programme. (January 2014). Water boiling test methods and product evaluation criteria. SOP 30.03.02. [Online]. Available: http://www.cleancookstoves.org/our-work/standards-and-testing/learn -about-testing-protocols/downloads/CSI_Indonesia_Test_Methods_20 14-1-14_v7.pdf

[16] N. N. Pratama, "Experimental study of waste plastics pyrolytic oil characteristics and its applications as alternative fuels on both diesel engines and pressurized cook stoves," M.S. thesis, Dept. Mechanical and Industrial Eng., Gadjah Mada Univ., Yogyakarta, Indonesia, 2013.

[17] P. T. Williams, "Yield and composition of gases and oils/waxes from the feedstock recycling of waste plastic," in Feedstock Recycling and Pyrolysis of Waste Plastics, Wiley Series in Polymer Science, J. Scheirs and W. Kaminsky, Eds. West Sussex: John Wiley and Sons, Ltd., 2006 , p. 304 .

[18] H. Saptoadi, A. K. Putra, W. Trisunaryanti, Z. Alimuddin, M. Syamsiro, and K. Yoshikawa, "Energy balance in non-catalytic pyrolysis of plastic wastes to produce liquid fuel," in Proc. AUN/SEED-Net Regional Conf. on Mechanical and Manufacture Engineering, 2013, pp. 13-20.

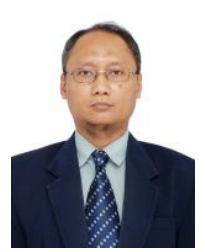

Harwin Saptoadi is a mechanical engineer. He was born in Denpasar, Indonesia on September 2, 1958. He got his engineer degree from Gadjah Mada University, Indonesia in 1985 , master of science degree in engineering from University of Michigan, USA in 1989, and finally doktor-ingenieur degree from Technical University of Clausthal, Germany in 1997. His undergraduate and master educations were focused on mechanical engineering, whereas the major field of doctoral study was energieverfahrenstechnik (energy process engineering). All of those education courses help him building up strong interests in energy and environment issues.

He works as a teaching staff and researcher at the Department of Mechanical and Industrial Engineering in Gadjah Mada University, Yogyakarta, Indonesia since 1986. Sometimes he serves as a consultant and trainer as well to carry out scientific requests from other institutions. He is a national reviewer of numerous papers prior to publications and research proposals prior to grant decisions. Since 2007 he takes responsibility as the director of Study Program in mechanical engineering for the second period. In 2010 he was awarded the full professorship from Ministry of Education and Culture, Republic of Indonesia. The prestigious recognition was a result of many publications in several research topics, such as solid combustions (including coal and biomass wastes), power plant analysis, plastics pyrolysis, energy conversion and efficiency.

Prof. Saptoadi is a member and declarator of SEE Forum since 2006. He is also active in the BKSTM because of his position as a study program director. 